\title{
Sacroiliitis during isotretinoin treatment: Causal association or coincidence?
}

\author{
(D) Ece Aydog, ${ }^{1}$ (D) Gulcan Ozturk, ${ }^{2}$ (D) Asuman Comert, ${ }^{3}$ (D) Neslihan Tasdelen, ${ }^{4}$ \\ (1) Ozlem Akin, ${ }^{3}$ (1) Duygu Geler Kulcu ${ }^{5}$ \\ ${ }^{1}$ Department of Physical Medicine and Rehabilitation, Yeditepe University Hospital, Istanbul, Turkey \\ ${ }^{2}$ Department of Physical Medicine and Rehabilitation, Fatih Sultan Mehmet Training and Research Hospital, Istanbul, Turkey \\ ${ }^{3}$ Department of Dermatology, Yeditepe University Hospital, Istanbul, Turkey \\ ${ }^{4}$ Department of Radiology, Yeditepe University Hospital, Istanbul, Turkey \\ ${ }^{5}$ Department of Physical Medicine and Rehabilitation, Haydarpasa Numune Training and Research Hospital, Istanbul, Turkey
}

\begin{abstract}
Isotretinoin, a retinoid derivate used in acne treatment, has a variety of side effects involving the musculoskeletal system; however, sacroiliitis is rarely observed. Our aim was to present nine cases of sacroiliitis in patients being treated with isotretinoin. Sacroiliitis was identified and monitored using magnetic resonance imaging (MRI). Clinical symptoms were resolved with nonsteroidal anti-inflammatory drug therapy after isotretinoin treatment was ceased. Different from the other cases, follow-up MRI was done. Follow-up MRI revealed improvement in some patients. Although the association between isotretinoin therapy and sacroiliitis has been covered in literature, this association is not yet completely understood. We aimed to discuss the relationship between two.
\end{abstract}

Keywords: Isotretinoin; sacroiliitis; side effect.

Cite this article as: Aydog E, Ozturk G, Comert A, Tasdelen N, Akin O, Geler Kulcu D. Sacroiliitis during isotretinoin treatment: Causal association or coincidence? North Clin Istanb 2019;6(1):75-80.

$\mathrm{I}^{\mathrm{s}}$ sotretinoin (13-cis-retinoic acid) is a retinoid derivative that is indicated for the treatment of severe nodulocystic acne and less severe but treatment-resistant acne [1]. The most commonly observed side effects of isotretinoin use are mucocutaneous and ocular reactions [2]. Approximately $16 \%$ of adults experience several musculoskeletal symptoms such as back pain, arthralgia, and/or myalgia [2]. Other uncommon musculoskeletal disorders have also been associated with retinoid therapy including hyperostosis, extraspinal calcifications, enthesopathy, arthritis, sacroiliitis, costochondritis, osteoporosis, growth retardation, and premature epiphyseal closure in children as well as gout $[2,3]$. Reactive sacroiliitis is a rare side effect of isotretinoin treatment.
A small number of cases of the sacroiliitis have been described in literature [4]. Here, we present nine cases of moderate-to-severe acne vulgaris in patients who also developed sacroiliitis during isotretinoin treatment and discuss the relationship between the two.

\section{CASE REPORT}

Case 1 - A 21-year-old female patient was started on a daily dose of $50 \mathrm{mg}$ isotretinoin therapy for facial acne. After 2 months of isotretinoin treatment, she began to experience pain in her lumbar region. Her pain increased with rest and decreased with exercise. She previously attended the orthopedic clinic and had a lumbar disc

Received: June 08, 2017 Accepted: February 07, 2018 Online: August 07, 2018

Correspondence: Dr. Gulcan OZTURK. Fatih Sultan Mehmet Egitim ve Arastirma Hastanesi, Fiziksel Tip ve Rehabilitasyon Bolumu, Istanbul, Turkey.

Phone: +90216578 4039 e-mail: drgul_can@hotmail.com

(c) Copyright 2019 by Istanbul Provincial Directorate of Health - Available online at www.northclinist.com 


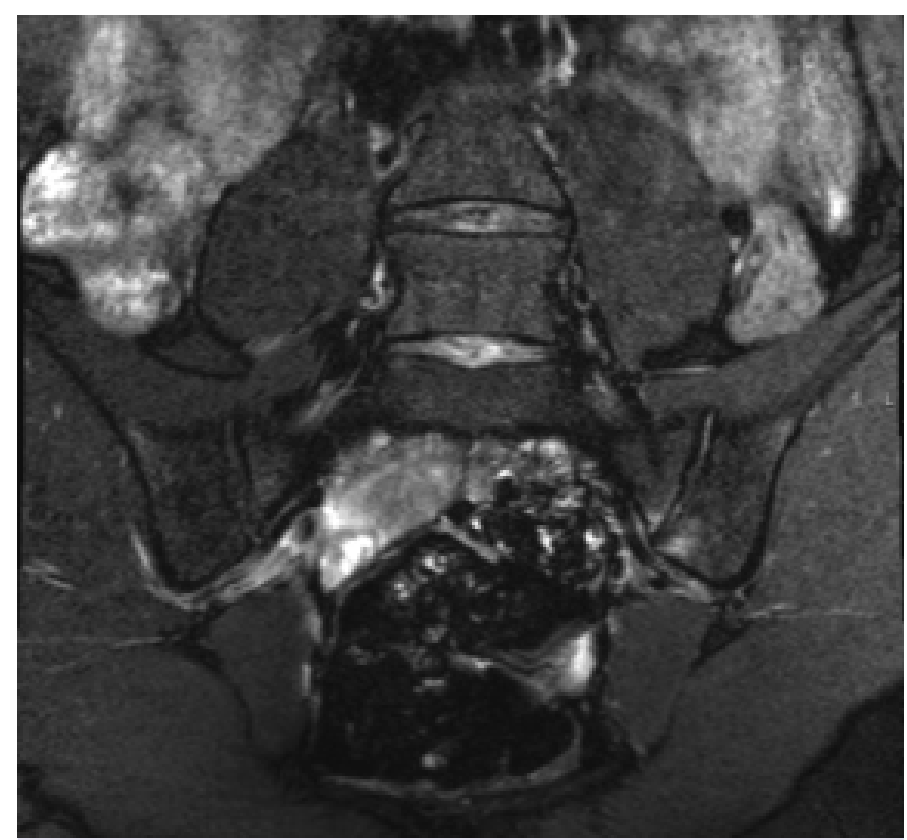

FIGURE 1. The magnetic resonance imaging shows bone marrow edema in the sacral and iliac wings of both the right and left sacroiliac joints.

herniation diagnosed. She underwent physical therapy for 15 sessions, although the pain continued. She then attended our outpatient clinic with the same complaints. On physical examination, lumbar flexion was restricted and painful with the sacroiliac stress test positive on the left side. The erythrocyte sedimentation rate (ESR) and $\mathrm{C}$-reactive protein (CRP) were measured in the normal range, and the patient was HLA B27 positive. Magnetic resonance imaging (MRI) of the sacroiliac joint revealed that bone marrow edema was detected in the sacral and iliac wings of both the right and left sacroiliac joints, consistent with active sacroiliitis (Fig. 1). A dermatology consultation was requested and isotretinoin treatment was ended after the $4^{\text {th }}$ month. Her complaints alleviated with nonsteroidal anti-inflammatory drug (NSAID) therapy after 2 weeks and her complaints resolved after 2 months.

Case 2 - A 29-year-old male patient was started on a daily dose of $40 \mathrm{mg}$ isotretinoin therapy for acne vulgaris on his face and upper trunk, which was continued for 6 months. 2 months after stopping isotretinoin therapy, he began to suffer from pain in his lumbar region, although he did not have morning stiffness. He had no history of low back pain before isotretinoin treatment. On physical examination, the range of lumbar motion was normal and painless with sacroiliac stress tests negative. ESR and
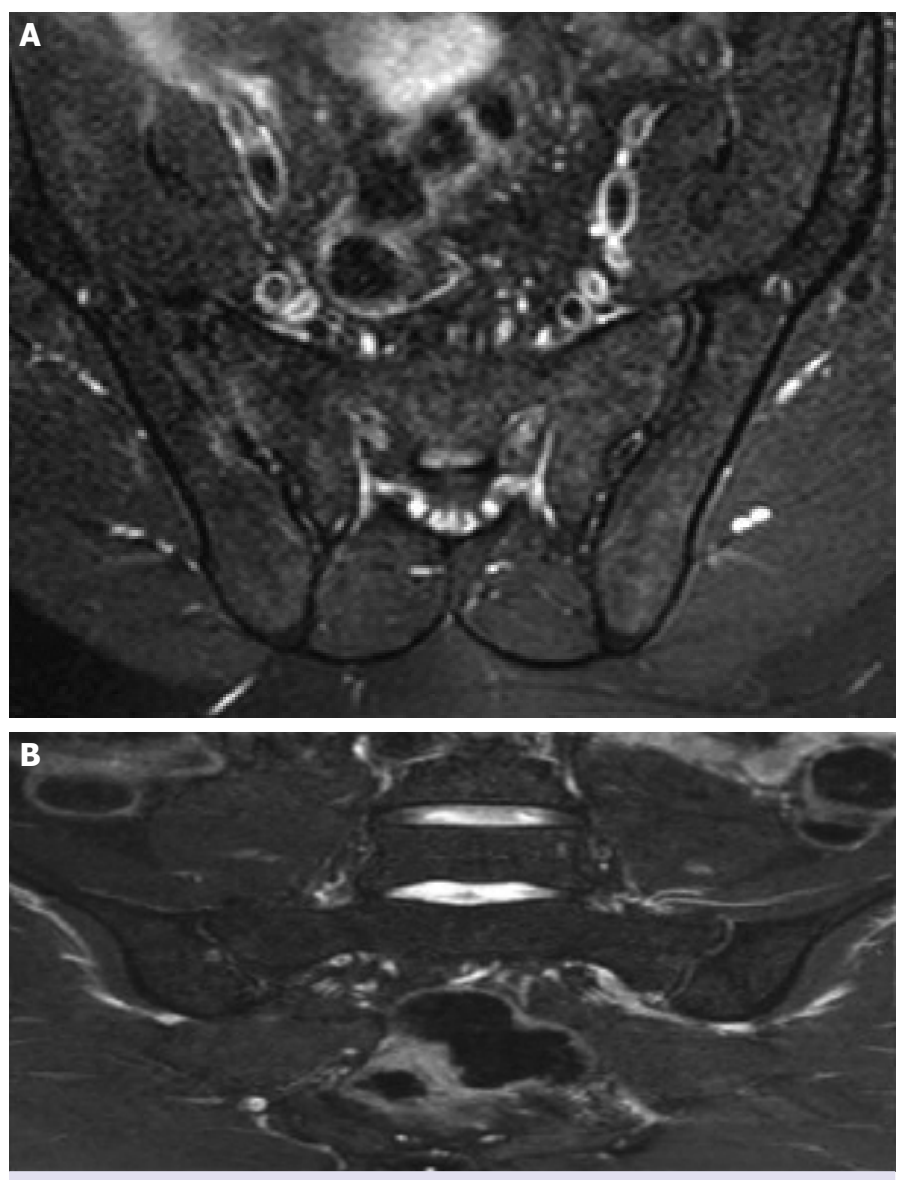

FIGURE2A, B. The magnetic resonance imaging shows bone marrow edema in the sacral and iliac wings of both the right and left sacroiliac joints and regression findings.

CRP were measured in the normal range, and the patient was HLA B27 negative. MRI of the sacroiliac joint revealed that bone marrow edema was detected in sacral and iliac wings of the right and left sacroiliac joint, consistent with active sacroiliitis (Fig. 2a). His complaints alleviated with NSAID therapy in a few months, and after 3 years, a sacroiliac MRI revealed regression (Fig. 2b). Case 3 - A 36-year-old female patient was started on a daily dose of $50 \mathrm{mg}$ isotretinoin therapy for facial acne. After 1 month, she began to suffer from pain in her lumbar and dorsal region. Her pain increased with rest and decreased with exercise, and her heel pain was significant in the morning. He had no history of low back pain before isotretinoin treatment. On physical examination, the range of lumbar motions was normal and painless. The flexion, abduction, and external rotation (FABER), extension test was positive on the left side. ESR and CRP were measured in normal range, and the patient was HLA B27 positive. MRI examination of the sacroil- 
iac joint revealed that bone marrow edema was bilaterally detected in the sacral and iliac wings of the sacroiliac joint, consistent with active sacroiliitis. A dermatology consultation was requested and isotretinoin treatment was ended and NSAID treatment commenced. Her pain decreased after 3 months and completely resolved after 6 months. After 2 years, her sacroiliac MRI was normal.

Case 4 - A 28-year-old woman started a daily dose of 25 $\mathrm{mg}$ isotretinoin for the treatment of acne vulgaris. In the 2nd month of treatment, she experienced hip and gluteal pain, which increased with rest and decreased with exercise. She also had morning stiffness lasting $1 \mathrm{~h}$. She had no history of low back pain before isotretinoin treatment. On physical examination, she had a decreased lumbar range of motion and the FABER test was positive on the right side. CRP and ESR were within the normal range and the patient was HLA B27 negative. MRI revealed bilateral bone marrow edema in sacral and iliac wings of both sacroiliac joints, consistent with active sacroiliitis (Fig. 3a). A dermatology consultation was requested and isotretinoin treatment discontinued and NSAID treatment started. Her complaints resolved after 1 year and did not recur. On control MRI after 2 years, a regression in a bone marrow edema of the sacroiliac joint was observed (Fig. 3b).

Case 5 - A 21-year-old female patient was started on a daily dose of $25 \mathrm{mg}$ isotretinoin therapy for facial acne. After 2 months of isotretinoin therapy, she began to suffer from pain in the lumbar region. Her pain increased with rest and decreased with exercise. She had pain at night but did not have morning stiffness. She had no history of low back pain before isotretinoin treatment. On physical examination, lumbar flexion was restricted and painful. ESR and CRP were in the normal range, and the patient was HLA B27 positive. MRI of the sacroiliac joint revealed that bone marrow edema was detected in the sacral and iliac wings of both the right and left sacroiliac joint, consistent with active sacroiliitis. A dermatology consultation was requested and the isotretinoin treatment was stopped and NSAID treatment started. 6 months later, she was free of symptoms. On a follow-up MRI, minimal bone marrow edema on the left sacroiliac joint was revealed after 1 year, which is compatible with a pattern of regression.

Case 6 - A 16-year-old man was started on a daily dose of $40 \mathrm{mg}$ isotretinoin for the treatment of acne vulgaris. His isotretinoin dosages were as follows: $40 \mathrm{mg} /$ daily for 4 months, 1 month $20 \mathrm{mg} /$ daily, and 2 months $40 \mathrm{mg} /$
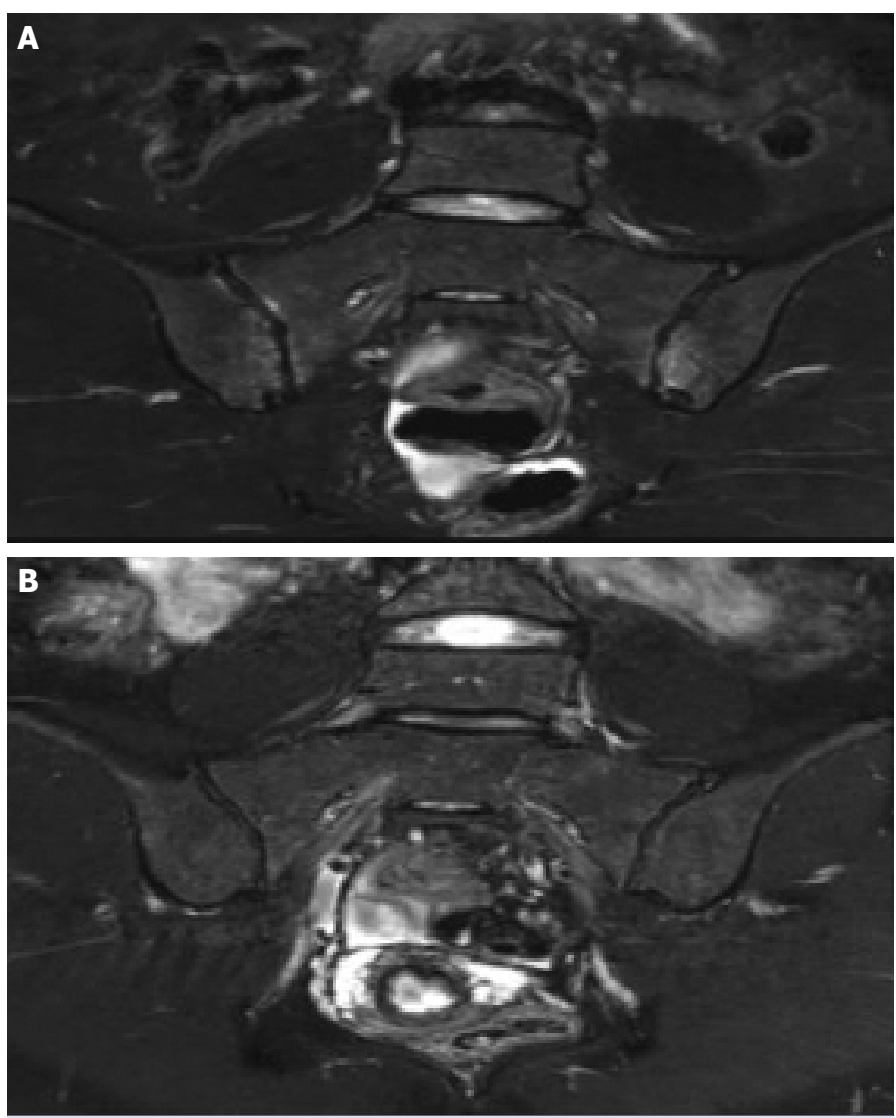

FIGURE $3 A, B$. The magnetic resonance imaging shows bone marrow edema in the sacral and iliac wings of both the right and left sacroiliac joints and regression findings.

daily. After the $7^{\text {th }}$ month of treatment, the patient developed lumbar pain. The pain increased with rest and decreased with exercise. He had morning stiffness lasting 1 $\mathrm{h}$. He had no history of low back pain before isotretinoin treatment. On physical examination, the range of lumbar motions was in the normal range, although it was painful. ESR and CRP values were normal, although the patient was HLA B27 positive. MRI revealed bilateral bone marrow edema in sacral and iliac wings of both sacroiliac joints, consistent with active sacroiliitis. A dermatology consultation was requested and the isotretinoin treatment was discontinued and NSAID therapy commenced. His complaints alleviated after a few weeks.

Case 7 - A 44-year-old female patient presented to the physical medicine and rehabilitation (PMR) outpatient clinic complaining of neck and lower back pain for several years. She had previously been diagnosed with fibromyalgia syndrome and was treated with pregabalin. She had taken isotretinoin treatment for acne vulgaris 7 years previously but did not mention any lower back pain 
while using isotretinoin. The pain increased with rest and decreased with exercise. She had a morning stiffness lasting $<1 \mathrm{~h}$. Examinations of the sacroiliac joint and lumbar region were normal. There were signs of fibrositis with pain localized to her back. ESR and CRP were within the normal range and the patient was HLA B27 negative. A sacroiliac MRI revealed bilateral bone marrow edema in anteroinferior sacroiliac joints, evident on the left side, consistent with active sacroiliitis. NSAID treatment was started and her complaints lessened but did not resolve. Her control MRI findings were similar compared with that 1 year ago.

Case 8 - A 28-year-old female patient presented to the PMR outpatient clinic complaining of back, chest, and hip pain for the past 5 years. A 5-month daily course of $50 \mathrm{mg}$ isotretinoin had been started 6 years ago for facial acne. Her pain was significant in the morning, increasing with rest, and decreasing with exercise. She had no history of low back pain before isotretinoin treatment. On physical examination, the range of lumbar motions was limited and painful. Sacroiliac provocation tests were positive on the right side. Both ESR and CRP were in the normal range and the patient was HLA B27 negative. MRI of the sacroiliac joint revealed that bilateral bone marrow edema in the sacral and iliac wings of the sacroiliac joint was detected, and erosions on the iliac and sacral face on both the right and left side were also revealed. The patient responded well to NSAID therapy and was symptom free a few months later.

Case 9 - A 36-year old female patient presented to the PMR outpatient clinic complaining of chest pain, which began 2 months previously. 16 years ago, at the age of 20 , a daily dose of $50 \mathrm{mg}$ isotretinoin therapy for 6 months was started for facial acne. She had lower back pain a few months after ending treatment, although the pain decreased with NSAID use a few months after this period. For 12 years, she had no complaints, but 4 years ago, she again took a daily dose of $50 \mathrm{mg}$ isotretinoin for 6 months. 2 months after stopping therapy, she had neck and back pain in addition to the lower back pain. She was treated with NSAIDs, methylprednisolone, and sulfasalazine. On physical examination, the range of lumbar motions was limited in all directions, and the range of neck motions was limited on flexion and extension. ESR and CRP were in the normal range and the patient was HLA B27 negative. MRI revealed bilateral bone marrow edema at the sacroiliac parts of the joints, consistent with active sacroiliitis. A home-based exercise program was added to the medical treatment. After 1 year, a control
MRI revealed signs of regression with the alleviation of the bilateral bone marrow edema at the sacroiliac parts of the joints.

\section{DISCUSSION}

Isotretinoin, a retinoid derivative indicated for the treatment of acne vulgaris, has multisystemic side effects. The most common side effects of isotretinoin involve the mucocutaneous and musculoskeletal system [5]. Musculoskeletal side effects include arthralgia, rhabdomyolysis, hyperostosis, osteolysis, ligamentous calcifications, and vasculitis [6]. In recent literature, sacroiliitis has been described as an uncommon side effect in case reports [6-12].

The etiology of rheumatic disorders associated with retinoids remains obscure, although it is presumed that immunomodulation by several mechanisms (such as an alteration in cytokine balance) is linked to this particular association [9]. As a result of its detergent-like effects, isotretinoin induces some alterations in the lysosomal membrane structure of cells, predisposing the synovial cells to a degenerative process. Isotretinoin treatment may render cells more sensitive to mild traumas, predisposing to injury [6].

The pathogenesis of sacroiliitis due to isotretinoin remains obscure; however, it is hypothesized that isotretinoin affects immunomodulation by several mechanisms including alteration of the cytokine balance. Isotretinoin has detergent-like effects and induces changes in lysosomal membrane structures, causing degeneration in synovial cells [6]. Levinson et al. [10] indicated that retinoic acid can activate matrix metalloproteinase 2 (MMP-2), causing synovial membrane degradation in joints. On the other hand, isotretinoin induces hypersensitivity reactions on cells, and synovial cells become sensitive to minor or mild traumas $[4,6]$.

Although isotretinoin could trigger sacroiliitis as a side effect, Eksioğlu et al. [7] indicated that HLA B27positive individuals may improve sacroiliitis. However, cases related to isotretinoin usage were usually HLA B27 negative in literature $[4,5,7,8,10,11]$. In our case series study, five of the nine patients were HLA B27 negative. According to literature and our case series study, it is possible to consider that there is not a clear relationship between HLA B27 positivity and sacroiliitis due to isotretinoin.

Acne fulminans $(\mathrm{AF})$ is a severe systemic form of acne 
vulgaris, characterized by a sudden onset, nodular acneic and ulcerative lesions accompanied with a systemic component including fever, arthralgia, and osteoarticular involvement [13]. Geller et al. [11] indicated that sacroiliitis following oral isotretinoin therapy could be associated with acne fulminans or adverse effects. Therefore, according to some authors, sacroiliitis can be a sign of acne fulminans, and it is not possible to exclude this possibility. In literature, sacroiliac joint involvement with arthritis has been observed in $21 \%$ of cases of the acne fulminans $[4,6]$. Our patients had nodulocystic acne rather than acne fulminans; therefore, difficult to decide whether sacroiliitis is a clinical presentation of acne fulminans.

According to our search of literature, this is the first case series study, indicating relationship between sacroiliitis and isotretinoin usage. Patients who have axial skeletal pain should be asked of their isotretinoin usage when considering a differential diagnosis. If isotretinoin usage is not ascertained, sacroiliitis could be overlooked. Consistent with literature and in our case series study, after a few months of medication, five of nine cases developed sacroiliitis a few months after medication, and one case developed sacroiliitis 2 months after ending medication. Therefore, it is considered as drug side effects in these six patients. The last three patients presented to our clinic with inflammatory axial pain with the use of isotretinoin, identified in their history. Since these patients could not remember exactly how long after isotretinoin use their lower back pain started, it is difficult to say if sacroiliitis developed due to isotretinoin treatment. However, we wanted to present these cases due to a possible association between isotretinoin and sacroiliitis.

Isotretinoin-related sacroiliitis usually responds to NSAID therapy after stopping isotretinoin usage. Bachmeyer et al., Dincer et al., [6] Eksioğlu et al., [7] and Levinson et al. [10] treated cases with NSAID, with the pain resolving in a few weeks. On the other hand, Rozin et al. combined NSAIDs with adrenocorticotropin (ACTH) injections [9]. Barbeschi et al. [8] treated bilateral sacroiliitis related to isotretinoin with NSAIDs, methylprednisolone, and sulfasalazine. Similar to literature, the cases in our study responded well to NSAID therapy and their pain resolved within a few weeks. Hughes et al. presented a patient with sacroiliitis whose biopsy revealed that synovial fluid was non-inflammatory in character. Contrary to Hughes, pain relief with NSAID suggests that the pain is inflammatory in character [14].
Six of the nine patients had MRI follow-up after 1 year, and we were unable to reach one of the patients. Two patients have been newly diagnosed newly. In the follow-up MRI findings, one patient had a normal sacroiliac joint, four showed regression, and one had chronic sacroiliitis. In literature, only a small number of reports on sacroiliitis due to isotretinoin had a sacroiliac MRI follow-up. Ekşioğlu et al. [7] reported fluctuating MRI findings 2 years after follow-up, and Yilmaz Tasdelen et al. [12] reported remission on MRI after 6 months. Therefore, there is a need for long-term studies to demonstrate regression in the sacroiliac joint on MRI.

In conclusion, patients with axial skeletal pain should be questioned about the use of isotretinoin, and clinicians should be aware of the possible association between isotretinoin and sacroiliitis.

Informed Consent: Written informed consent was obtained from the patients for the publication of the case report and the accompanying images.

Conflict of Interest: No conflict of interest was declared by the authors.

Financial Disclosure: The authors declared that this study has received no financial support.

Authorship Contributions: Concept - G.O., E.A.; Design - G.O., E.A., A.C., O.A.; Supervision - E.A., A.C., D.G.K.; Materials - N.T., G.O.; Data collection \&/or processing - E.A., G.O., A.C.; Analysis and/or interpretation - E.A., G.O., A.C.; Writing - E.A., G.O., A.C., N.T.; Critical review - E.A., O.A., A.C., D.G.K.

\section{REFERENCES}

1. Thiboutot D, Gollnick H, Bettoli V, Dréno B, Kang S, Leyden JJ, et al. New insights into the management of acne: An update from the global alliance to improve outcomes in acne group. J Am Acad Dermatol 2009;60:S1-50. [CrossRef]

2. Lowenstein EB, Lowenstein EJ. Isotretinoin systemic therapy and the shadow cast upon dermatology's downtrodden hero. Clin Dermatol 2011;29:652-61. [CrossRef]

3. Pedraz T, Martínez A, Pascual E. Acute hip monoarthritis in a patient treated with isotretinoin. J Clin Rheumatol 2006;12:105-6. [CrossRef]

4. Bachmeyer C, Charoud A, Turc Y, Callot V, Blum L, Aractingi S, et al. Isotretinoin-induced bilateral sacroiliitis. Dermatology 2003;206:285-6.

5. Yılmazer B, Coşan, Kefle A. Bilateral acute sacroiliitis due to isotretinoin therapy: A case report. Int J Rheum Dis 2013;16:604-5.

6. Dinçer U, Çakar E, Kıralp MZ, Dursun H. Can isotretinoin induce sacroiliitis: Three cases. Romatizma 2008;23:157-159.

7. Eksioglu E, Oztekin F, Unlu E, Cakci A, Keyik B, Karadavut IK, et al. Sacroiliitis and polyneuropathy during isotretinoin treatment. Clin Exp Dermatol 2008;33:122-4. [CrossRef]

8. Barbareschi M, Paresce E, Chiaratti A, Ferla Lodigiani A, Clerici G, Greppi F, et al. Unilateral sacroiliitis associated with systemic isotretinoin treatment. Int J Dermatol 2010;49:331-3. [CrossRef]

9. Rozin AP, Kagna O, Shiller Y. Sacroiliitis and severe disability due to 
isotretinoin therapy. Rheumatol Int 2010;30:985-6. [CrossRef]

10. Levinson M, Gibson A, Stephenson G. Sacroiliitis secondary to isotretinoin. Australas J Dermatol 2012;53:298-300. [CrossRef]

11. Geller AS, Alagia RF. Sacroiliitis after use of oral isotretinoin - Association with acne fulminans or adverse effect? An Bras Dermatol 2013;88:193-6. [CrossRef]

12. Yilmaz Tasdelen O, Yurdakul FG, Duran S, Bodur H. Isotretinoin-in- duced arthritis mimicking both rheumatoid arthritis and axial spondyloarthritis. Int J Rheum Dis 2015;18:466-9. [CrossRef]

13. Zaba R, Schwartz R, Jarmuda S, Czarnecka-Operacz M, Silny W. Acne fulminans: Explosive systemic form of acne. J Eur Acad Dermatol Venereol 2011;25:501-7. [CrossRef]

14. Hughes RA. Arthritis precipitated by isotretinoin treatment for acne vulgaris. J Rheumatol 1993;20:1241-2. 